\title{
Tracking the Sustainability of Improvements in Hospital Outcomes
}

\author{
Ronald Lagoe, Ruthie Lagoe \\ Hospital Executive Council, Syracuse, USA \\ Email: hospexcl@cnymail.com \\ Received 17 August 2014; revised 18 September 2014; accepted 21 October 2014 \\ Copyright (C) 2014 by authors and Scientific Research Publishing Inc. \\ This work is licensed under the Creative Commons Attribution International License (CC BY). \\ http://creativecommons.org/licenses/by/4.0/

(c) (i) Open Access

\section{Abstract}

This study focused on tracking the sustainability of improvements in inpatient outcomes in the hospitals of Syracuse, New York. It involved evaluation of inpatient complications during a sixyear period for two of the Syracuse hospitals and inpatient readmissions during a three-year period for three hospitals. The study employed the Potentially Preventable Complications and Potentially Preventable Readmissions software developed by $3 \mathrm{M}^{\mathrm{TM}}$ Health Information Systems. The study demonstrated that two of the Syracuse hospitals produced reductions in aggregate complication rates between 2009 and 2012 . This was followed by an increase in complications during 2013 and 2014. The decline in complications and the increase that followed were supported by developments in high volume complications and some lower volume complications. Hospital readmissions for adult medicine, the largest inpatient service, both increased and declined at the aggregate level and for individual hospitals during the three-year period. Hospital readmission rates for adult surgery declined, however, individual hospital rates increased and declined. The study identified sustained reductions in readmission rates for the combined hospitals for congestive heart failure and COPD during the three-year period. The study identified the challenges related to sustaining reductions in hospital outcomes over time. In the Syracuse hospitals, these challenges involved inpatient clinical management for complications and system-wide issues for readmissions.

\section{Keywords}

Hospital Outcomes, Hospital Complications, Hospital Readmissions

\section{Introduction}

In the United States and western Europe, increased interest is focusing on health care cost containment. As large proportions of national expenditures are consumed by health care costs, greater attention is being devoted to im- 
proving the efficiency of care [1]-[3].

This attention has also generated extensive interest in the connection between health care efficiency and improved outcomes. This has been based on recognition that positive outcomes can reduce costs by reducing the amount of care that needs to be provided. It has also generated support for moving the basis of health care and hospital reimbursement from volume to value. This has been reflected in initiatives by Medicare and other payors to penalize hospitals for adverse outcomes such as excess readmissions [4]-[6].

The increasing importance of health care and hospital outcomes is related to the need to sustain outcomes over time. Without efforts that sustain improvements in complications, readmissions, and other outcomes, they become one-time benefits for consumers and providers of care.

Recent efforts to improve health care outcomes have focused on two important indicators: hospital inpatient complications and readmissions. Both of these outcomes have been associated with large volumes of adverse outcomes and related costs [7]-[9].

Both complications and readmissions are being addressed by relatively new computer software, such as Potentially Preventable Complications and Potentially Preventable Readmissions that provide extensive information from administrative data. The information developed by this software can support efforts to reduce complications and readmissions. Because the software uses administrative data, it can be used to employ large numbers of patients using standardized definitions over time. These advantages are especially useful in monitoring sustainability of outcomes. These tools can monitor large amounts of data from multiple hospitals over extended time periods [10]-[12].

\section{Population and Methods}

This study focused on tracking the sustainability of improvements in hospital outcomes in the hospitals of Syracuse, New York. These acute care facilities include Crouse Hospital (19,738 discharges excluding well newborns, 2013), St. Joseph’s Hospital Health Center (25,771 discharges, 2013), and Upstate University Hospital (27,285 discharges, 2013). These hospitals provide acute care to a local service area of approximately 600,000 and serve as the referral center for the Central New York Health Service area, with a population of approximately 1,400,000. Historically, the hospitals have worked cooperatively to improve utilization and outcomes through the Hospital Executive Council [13].

The study identified changes in inpatient complications during a six-year period for two of the Syracuse hospitals and inpatient readmissions over a three-year period for the three hospitals. The analyses for the study were developed by the Hospital Executive Council. The study also evaluated the use of the Potentially Preventable Complications and Potentially Preventable Readmission software to track changes in these outcomes over multiple year periods.

The study design and procedures were developed by the Hospital Executive Council and the administrative staffs of Crouse Hospital, St. Joseph's Hospital Health Center, and Upstate University Hospital in Syracuse, New York. Multihospital utilization and outcomes studies are developed and implemented by these entities.

The study was related to demonstration programs using the Potentially Preventable Complications and Potentially Preventable Readmissions software. These programs employed the software to improve outcomes through cooperation of the Syracuse hospitals, 3M $\mathrm{M}^{\mathrm{TM}}$ Health Information Systems, and the Hospital Executive Council [14] [15].

The initial component of the study involved post admission complications in Syracuse. It employed the Potentially Preventable Complications (PPC) software. The PPC system provides standardized information on a full range of diagnoses that can occur after inpatient admission. It includes a list of 64 categories that has been condensed to a summary list of 35 PPCs. The software excludes a number of diagnoses as non preventable including complications directly related to malignant diseases, multiple trauma, organ transplants, burns, and HIV related disorders [10] [16] [17].

The PPC software identifies complications that occur after inpatient admission in administrative data. It applies the Present on Admission indicator to each secondary diagnosis. Each of these diagnoses is identified as present on admission, not present on admission, or undetermined. It can generate numbers of complications and rates for individual diagnoses and for all PPCs combined [10].

In the analysis of data for the Syracuse hospitals, the PPC software was employed to identify numbers and rates of post admission complications for St. Joseph's Hospital Health Center and Crouse Hospital between 2009 
and 2014. The data were identified for January-December for 2009-2013 and for January-March for 2014. These data were based on all payors for inpatient discharges.

Within these parameters, the PPC software was used by the Hospital Executive Council staff to identify numbers and rates of complications for all PPCs combined. The software also identified numbers and rates of complications for high volume diagnoses including pneumonia and urinary tract infection. The software also identified these indicators for low volume diagnoses including clostridium difficile colitis, pulmonary embolism, and septicemia.

These data were used to evaluate the sustainability of improvements in outcomes for these complications. Rates for Potentially Presentable Complications were compared across the period between January 2009 and March 2014 for each hospital. Initial comparisons focused on the aggregate rates for the individual PPCs combined. Subsequent analyses focused on rates for individual high and low volume complications. These comparisons were employed to develop conclusions concerning the sustainability of these outcomes.

The second component of the study involved hospital inpatient readmissions at Crouse Hospital, St. Joseph's Hospital Health Center, and Upstate University Hospital in Syracuse. It included readmissions for adult medicine and adult surgery, the two largest inpatient services in the hospitals.

The study employed the Potentially Preventable Readmissions (PPR) software developed by $3 \mathrm{M}^{\mathrm{TM}}$ Health Information Systems. The PPR system provides standardized information concerning patients who return to acute hospitals that are identified as preventable according to a clinical algorithm. Readmissions identified as preventable are those with principal diagnoses that are clinically related to the principal or secondary diagnoses of the initial admission. Readmissions with principal diagnoses not related to those of the initial admission are assumed to be non preventable. In addition, readmissions for a number of specific services, including oncology, neonates, trauma, and HIV related disorders are assumed to be non preventable [12] [18].

The Potentially Preventable Readmissions software includes readmission chains. A chain is defined as an initial admission followed by at least one readmission for inpatient care within a specific time period, usually 30 days. Total readmissions can be aggregated by hospital service, by diagnosis, by discharge status, or other categories.

For purposes of this analysis, readmissions were defined as individual returns for inpatient care in each of the three Syracuse hospitals that occurred within 30 days of the previous admission. Consistent with the PPR software, only preventable readmissions were included. They accounted for more than 90 percent of all readmissions in the Syracuse hospitals.

In order to evaluate the sustainability of improvements in hospital readmissions, the study included these outcomes in Syracuse during a three year period, from April 2011-March 2012 to April 2013 to March 2014. This time interval provided the most current information concerning hospital readmissions using administrative, computer abstracted data. These data were based on inpatient discharges for all payors.

Within this time interval, numbers of Potentially Preventable Readmissions and Readmission rates were identified by the Hospital Executive Council staff for each Syracuse hospital and the combined hospitals by service and diagnosis. This analysis included the two largest services, adult medicine and adult surgery, and two major chronic diagnoses that have been identified as major sources of readmissions, heart failure and chronic obstructive pulmonary diagnoses. These classifications were identified using All Patients Refined Diagnosis Related Groups.

These data were used to evaluate the sustainability of hospital outcomes for readmissions over time for each hospital and the three hospitals combined. Conclusions were based on the consistency of improvements in outcomes over time.

\section{Results}

Results that are related to the initial component of the study, which concerns the sustainability of hospital inpatient complications, are summarized in Table 1. This information includes data for Crouse Hospital and St. Joseph's Hospital Health Center.

These data demonstrated that each of the hospitals produced substantial reductions in aggregate complication rates, discharges with one or more Potentially Preventable Complications, between 2009 and 2012. The total rate for Crouse Hospital declined by 34.0 percent and the total rate for St. Joseph’s Hospital Health Center declined by 41.6 percent, during this interval. These rates reflected smaller percentage changes in numbers of complications as discharge volumes increased. 
Table 1. Potentially Preventable Complications, Syracuse Hospitals, January-December 2009-2013, January-March 2014.

\begin{tabular}{|c|c|c|c|c|c|c|c|c|c|c|c|c|c|}
\hline & \multicolumn{6}{|c|}{ Number of Patients with Complication } & \multicolumn{7}{|c|}{ Major PPC Rate per 1000 Discharges } \\
\hline & 2009 & 2010 & 2011 & 2012 & 2013 & 1Q 2014 & 2009 & 2010 & 2011 & 2012 & 2013 & 1Q 2014 & \\
\hline \multicolumn{14}{|l|}{ Crouse Hospital } \\
\hline Discharges w/One or More PPCs & 693 & 697 & 745 & 687 & 679 & 177 & 42.65 & 37.14 & 34.14 & 28.13 & 29.12 & 32.16 & \\
\hline Pneumonia (PPC 04) & 79 & 82 & 61 & 53 & 59 & 14 & 6.40 & 5.73 & 4.21 & 3.68 & 4.38 & 4.54 & 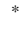 \\
\hline Urinary Tract Infection (PPC 16) & 127 & 116 & 150 & 124 & 109 & 28 & 8.80 & 7.21 & 9.30 & 7.68 & 7.14 & 7.76 & \\
\hline Clostridium Difficile Colitis (PPC 15) & 25 & 29 & 37 & 28 & 30 & 5 & 1.67 & 1.67 & 2.09 & 1.59 & 1.80 & 1.28 & \\
\hline Pulmonary Embolism (PPC 06) & 13 & 24 & 16 & 18 & 15 & 7 & 0.88 & 1.40 & 0.92 & 1.03 & 0.91 & 1.81 & \\
\hline Septicemia (PPC 20) & 53 & 40 & 46 & 36 & 47 & 12 & 3.65 & 2.36 & 2.69 & 2.11 & 2.93 & 3.24 & T \\
\hline \multicolumn{14}{|l|}{ St. Joseph’s Hospital Health Center } \\
\hline Discharges w/One or More PPCs & 993 & 1,026 & 896 & 904 & 902 & 264 & 56.31 & 47.28 & 37.37 & 32.91 & 33.31 & 39.70 & * \\
\hline Pneumonia (PPC 04) & 175 & 168 & 128 & 145 & 162 & 47 & 13.16 & 10.85 & 7.64 & 8.15 & 9.25 & 11.19 & * \\
\hline Urinary Tract Infection (PPC 16) & 145 & 162 & 127 & 112 & 108 & 37 & 9.03 & 8.78 & 6.39 & 5.29 & 5.15 & 7.27 & \\
\hline Clostridium Difficile Colitis (PPC 15) & 38 & 74 & 85 & 58 & 62 & 20 & 2.20 & 3.71 & 3.98 & 2.52 & 2.74 & 3.62 & \\
\hline Pulmonary Embolism (PPC 06) & 20 & 22 & 25 & 25 & 13 & 5 & 1.17 & 1.11 & 1.18 & 1.10 & 0.58 & 0.91 & \\
\hline Septicemia (PPC 20) & 102 & 103 & 73 & 35 & 31 & 17 & 6.08 & 5.29 & 3.50 & 1.56 & 1.41 & 3.20 & \\
\hline
\end{tabular}

${ }^{*}$ Statistically significant at 0.05 level.

The data also demonstrated that neither hospital was able to sustain these outcomes beyond the four-year period. Between 2012 and January-March 2014, the aggregate Potentially Preventable Complications rate at Crouse Hospital increased by 14.3 percent, while the rate at St. Joseph's Hospital Health Center increased by 20.6 percent. The increase at St. Joseph’s Hospital Health Center offset almost half of the reduction that occurred between 2009 and 2012.

Further analysis of the hospital data for high and low volume Potentially Preventable Complications suggested some of the drivers of the changes in the aggregate data. At Crouse Hospital, the reduction in the aggregate complication rate that occurred between 2009 and 2012 was accompanied by reductions in the rates for high volume diagnoses such as urinary tract infection (12.7 percent) and pneumonia (42.5 percent). At St. Joseph's Hospital Health Center, the reduction in the aggregate PPC rate during this interval was associated with declines in the rates for high volume diagnoses such as pneumonia (38.1 percent) and urinary tract infection (41.4 percent).

The data also demonstrated that the increases in the aggregate PPC rates that occurred between 2012 and 2014 were accompanied by increases in the rates for these high volume complications, especially pneumonia. During this interval, at Crouse Hospital the rate for pneumonia increased by 23.3 percent while the rate for urinary tract infection increased by 1.0 percent. At St. Joseph's Hospital Health Center, the rate for pneumonia increased by 37.3 percent, while the rate for urinary tract infection increased by 37.4 percent.

The study data also identified changes in PPC rates for lower volume complications that paralleled most changes in the aggregate rates. At Crouse Hospital, the complication rates declined for clostridium difficile colitis (4.8 percent) and septicemia (42.2 percent) between 2009 and 2012. At St. Joseph's Hospital Health Center, the PPC rates for pulmonary embolism (6.0 percent) and septicemia (74.3 percent) declined during this interval. At Crouse Hospital, the complication rates increased for pulmonary embolism (75.7 percent) and septicemia (53.6 percent) between 2012 and 2014. At St. Joseph's Hospital Health Center, the rates for clostridium difficile colitis (43.7 percent) and septicemia (105.1 percent) increased during this interval.

These data demonstrated that Crouse Hospital and St. Joseph's Hospital Health Center were able to generate substantial reductions in Potentially Preventable Complication rates between 2009 and 2012, but were unable to sustain these reductions during the next two years. At both hospitals, high volume complications, especially 
pneumonia, and some lower volume complications were drivers of the initial reductions in rates and the increases that followed.

Results of the study that are related to the second component of the study, which concerns the sustainability of Potentially Preventable Readmissions to hospitals within 30 days, are summarized in Table 2 and Table 3. This information includes data for Crouse Hospital, St. Joseph's Hospital Health Center, and University Hospital.

The data in Table 2 identified numbers and rates of Potentially Preventable Readmissions for the major hospital services during the most recent three-year period available. Data for the combined hospitals indicated that, during this period, more than 90 percent of medical-surgical admissions involved adult medicine patients. In the most recent year (April 2013-March 2014), 11 percent of adult medicine patients in the combined hospitals were readmitted. As a result, one of every nine adult medicine inpatients was a readmission.

With respect to sustainability, the combined hospital adult medicine readmission rate, which accounted for most rehospitalizations, decreased by 3.4 percent for 2011-2012 and 2012-2013, then increased by 2.9 percent between 2012-2013 and 2013-2014. Among the individual hospitals, reductions in readmissions rates were generally not sustained for these services. The rates for adult medicine, which generated the largest volumes, declined then increased at Crouse Hospital and Upstate University Hospital during the three-year period. The rate for St. Joseph's Hospital Health Center declined, however that hospital had the highest rate in Syracuse throughout the period.

For adult surgery, the combined readmission rate for the three hospitals decreased by 5.1 percent during the three-year period. For the individual hospitals, the adult surgery readmission rates declined, then increased at Crouse Hospital and St. Joseph’s Hospital Health Center, while they increased then declined at Upstate University Hospital.

The data in Table 3 concerned Potentially Preventable Readmissions for two major adult medicine diagnoses in the Syracuse hospitals. The rate for congestive heart failure for the combined hospitals between April 2013 and March 2014, 21.17 percent, suggested that one in five hospital inpatients with this diagnosis was a readmission. The rate for chronic obstructive pulmonary disease during the same period, 13.81 percent, suggested that one in seven inpatients with this diagnosis was a readmission.

At the aggregate level, the rate for congestive heart failure declined from year to year during the period, producing a total reduction of 14.6 percent. This reduction was generated by a 21.5 percent decline in the rate for

Table 2. Potentially Preventable Readmission Rates, Adult Medicine and Adult Surgery, Syracuse Hospitals, April 2011March 2014.

\begin{tabular}{|c|c|c|c|c|c|c|c|}
\hline & \multicolumn{3}{|c|}{ Number of Total Readmissions } & \multicolumn{3}{|c|}{ Total Readmission Rates } & \multirow{2}{*}{$\begin{array}{l}\text { Percent Change } \\
\text { Apr 11-Mar } 12 \text { vs. } \\
\text { Apr 13-Mar } 14\end{array}$} \\
\hline & $\begin{array}{l}\text { Apr 11- } \\
\text { Mar } 12\end{array}$ & $\begin{array}{l}\text { Apr 12- } \\
\text { Mar } 13\end{array}$ & $\begin{array}{l}\text { Apr 13- } \\
\text { Mar } 14\end{array}$ & $\begin{array}{l}\text { Apr 11- } \\
\text { Mar } 12\end{array}$ & $\begin{array}{l}\text { Apr 12- } \\
\text { Mar } 13\end{array}$ & $\begin{array}{l}\text { Apr 13- } \\
\text { Mar } 14\end{array}$ & \\
\hline \multicolumn{8}{|l|}{ Adult Medicine } \\
\hline Crouse Hospital & 925 & 776 & 854 & 9.99 & 8.70 & 10.21 & 2.20 \\
\hline $\begin{array}{l}\text { St. Joseph’s Hospital } \\
\text { Health Center }\end{array}$ & 1647 & 1787 & 1592 & 12.00 & 12.34 & 11.41 & -4.92 \\
\hline $\begin{array}{l}\text { Upstate University } \\
\text { Hospital-Downtown Campus }\end{array}$ & 1047 & 1068 & 1100 & 10.59 & 9.96 & 10.92 & 3.12 \\
\hline Total & 3619 & 3631 & 3546 & 11.01 & 10.64 & 10.95 & -0.54 \\
\hline \multicolumn{8}{|l|}{ Adult Surgery } \\
\hline Crouse Hospital & 67 & 66 & 76 & 1.62 & 1.46 & 1.76 & 8.64 \\
\hline $\begin{array}{l}\text { St. Joseph’s Hospital } \\
\text { Health Center }\end{array}$ & 114 & 111 & 123 & 1.69 & 1.44 & 1.52 & -10.06 \\
\hline $\begin{array}{l}\text { Upstate University } \\
\text { Hospital-Downtown Campus }\end{array}$ & 98 & 115 & 85 & 2.02 & 2.40 & 1.88 & -6.93 \\
\hline Total & 279 & 292 & 284 & 1.77 & 1.72 & 1.68 & -5.08 \\
\hline
\end{tabular}

Based on 3M Health Information Systems Potentially Preventable Readmissions algorithm applied to adult medicine and adult surgery definitions by APR DRG for readmissions within 30 days. 
Table 3. Potentially Preventable Readmission Rates, congestive heart failure (APR DRG 194) and chronic obstructive pulmonary disease (APR DRG 140), Syracuse Hospitals, April 2011-March 2014.

\begin{tabular}{|c|c|c|c|c|c|c|c|c|}
\hline & \multicolumn{3}{|c|}{ Total Number of Readmissions } & \multicolumn{3}{|c|}{ Total Readmission Rates } & \multirow{2}{*}{\multicolumn{2}{|c|}{$\begin{array}{c}\text { Percent Change } \\
\text { Apr 11-Mar } 12 \text { vs. } \\
\text { Apr 13-Mar } 14\end{array}$}} \\
\hline & $\begin{array}{l}\text { Apr 11- } \\
\text { Mar } 12\end{array}$ & $\begin{array}{l}\text { Apr 12- } \\
\text { Mar } 13\end{array}$ & $\begin{array}{l}\text { Apr 13- } \\
\text { Mar } 14\end{array}$ & $\begin{array}{l}\text { Apr 11- } \\
\text { Mar } 12\end{array}$ & $\begin{array}{l}\text { Apr 12- } \\
\text { Mar } 13\end{array}$ & $\begin{array}{l}\text { Apr 13- } \\
\text { Mar } 14\end{array}$ & & \\
\hline \multicolumn{9}{|l|}{ Congestive Heart Failure } \\
\hline Crouse Hospital & 106 & 79 & 71 & 24.71 & 20.68 & 19.40 & * & -21.49 \\
\hline St. Joseph’s Hospital Health Center & 189 & 225 & 176 & 25.51 & 25.54 & 21.65 & * & -15.13 \\
\hline $\begin{array}{l}\text { Upstate University } \\
\text { Hospital-Downtown Campus }\end{array}$ & 62 & 57 & 61 & 22.96 & 19.52 & 22.10 & & -3.75 \\
\hline Total & 357 & 361 & 308 & 24.79 & 23.22 & 21.17 & * & -14.60 \\
\hline \multicolumn{9}{|l|}{ Chronic Obstructive Pulmonary Disease } \\
\hline Crouse Hospital & 46 & 35 & 28 & 15.13 & 11.82 & 12.50 & * & -17.38 \\
\hline St. Joseph’s Hospital Health Center & 114 & 127 & 76 & 19.93 & 17.09 & 13.82 & * & -30.66 \\
\hline $\begin{array}{l}\text { Upstate University } \\
\text { Hospital-Downtown Campus }\end{array}$ & 32 & 19 & 24 & 15.38 & 10.86 & 15.69 & & 2.02 \\
\hline Total & 192 & 181 & 128 & 17.71 & 14.91 & 13.81 & * & -22.02 \\
\hline
\end{tabular}

Based on 3M Health Information Systems Potentially Preventable Readmissions algorithm by APR DRG for readmissions within 30 days. ${ }^{*}$ Statistically significant at .05 level.

Crouse Hospital, a 15.1 percent reduction for St. Joseph’s Hospital Health Center, and a 3.8 percent decline for Upstate University Hospital. The reduction at Crouse Hospital involved year to year declines throughout the period.

The aggregate data for Chronic Obstructive Pulmonary Disease also identified year to year declines during the three year period. This resulted in a reduction in the readmission rate for the combined hospitals of 22.0 percent. The decline in the total readmission rate for this diagnosis was driven by a 30.7 percent reduction at St. Joseph's Hospital Health Center and a 17.4 percent reduction at Crouse Hospital. The decline at St. Joseph's Hospital Health Center involved year to year reductions during the three year period.

\section{Discussion}

Increased attention is focusing on improving health care outcomes in order to support patient care and to reduce expenditures. This subject is related to the need for sustainability of these improvements so that their benefits for patients and communities will continue over time. Without sustainability, the improvements in care and financial savings related to outcomes become one time benefits.

This study involved the use of relatively new computer software and administrative rates to track changes in hospital inpatient complications and readmissions during a multiyear interval. The Potentially Preventable Complications software is based on the Present on Admission indicator. The Potentially Preventable Readmission software is based on standard clinical and utilization indicators. Both of these algorithms were developed for use with administrative data. Through this capability, they can analyze large numbers of hospital inpatient records over extended time periods. In this role, they are extremely useful in tracking the sustainability of hospital readmissions and complications.

With respect to inpatient complications, this study demonstrated that two of the Syracuse hospitals produced reductions in aggregate complication rates during a four-year period between 2009 and 2012. The data suggested that this interval was the extent of sustainability for this outcome, because complications increased during 2013 and 2014. Both the decline in complications and the increase that followed appeared to be supported by developments in high volume complications such as pneumonia and urinary tract infection, as well as some lower volume complications. 
With respect to inpatient readmissions, the study identified at least two developments. For the hospital service with the largest number of readmissions, adult medicine, the combined readmission rate and the individual hospital rates both increased and declined during the three-year period between April 2012-March 2013 and April 2013-March 2014. The combined readmission rates for adult surgery declined from year to year during this period, however, the rates for each of the hospitals both increased and declined.

The study identified sustained reductions in readmission rates for the combined hospitals during the threeyear period for congestive heart failure and chronic obstructive pulmonary disease. These reductions were reflected in the experiences of some of the hospitals for each diagnosis.

These data identified some of the challenges associated with sustaining improvements in hospital outcomes at the community level in Syracuse, New York and, possibly in other metropolitan areas. The reasons for these challenges could be suggested from the data and from anecdotal evidence from the hospitals.

The study data suggested that these outcomes affected relatively small minorities of hospital inpatient populations. This was especially true for total complications, where total rates ranged between 2 and 4 percent and readmissions by service, where rates ranged between 10 and 12 percent for adult medicine and between 1 and 2 percent for adult surgery. Higher rates were identified for individual diagnoses, especially for readmissions involving chronic diseases.

An important challenge to the sustainability of these hospital inpatient complications involved maintaining clinical practices that supported effective care within hospital environments. For example, the extent of compliance for nursing initiatives to avoid the pneumonia complication such as early ambulation of patients increased between 2009 and 2012, then, progressively declined in one of the Syracuse hospitals. Difficulties in sustaining physician and nursing compliance with interventions to avoid complications proved to be a problem in both hospitals. Much of this problem apparently resulted from the inability of hospital managements and staffs to maintain a focus of care on specific interventions and practices. Distractions within hospital environments, such as the implementation of new programs, provided too much competition for these efforts over time.

With respect to improvements in hospital readmissions, major challenges to sustainability in Syracuse involved systems issues. Primary care practices were frequently unable to accommodate patients with chronic diseases who experienced acute episodes. They frequently referred these patients to hospital emergency departments. Hospital clinics were only available during daytime hours, a problem frequently encountered in small metropolitan areas. Hospital emergency departments were frequently crowded and did not have the time available to develop alternative plans to inpatient admission of potential readmissions. In these crowded situations, the most feasible alternative for emergency department physicians was frequently inpatient admission.

These challenges suggest that, unless the experiences of Syracuse are unique, sustaining improvements in outcomes will be a difficult task for many hospitals in the United States and elsewhere. The transition from volume to value that has currently been called for at many levels of health care will require much more effort in the clinical trenches than that has been currently forthcoming. This process will need a management focus on improving complications and readmissions that is more consistent over time than what currently exists. Resources such as the Potentially Preventable Complications and Potentially Preventable Readmissions software can provide valuable support for this process. At the same time, these resources cannot sustain improvements in care by themselves. In addition to generating positive outcomes initially, this process requires actually using the data generated by the software in the nursing units and the emergency departments to sustain these outcomes over extended periods of time.

\section{Limitations}

The methods and results of this study were limited to data concerning inpatient complications for 2009-2014 and inpatient readmissions for 2011-2014 in the hospitals of Syracuse, New York. They were also limited to the use of the Potentially Preventable Complications and Potentially Preventable Readmissions software in the analysis of these data.

\section{Recommendations}

Based on the data contained in this study, it was recommended that hospitals evaluate and monitor changes in inpatient complications and readmissions using analytical tools that were specifically developed for this purpose. It is recommended that increases or reductions in outcomes identified by these tools be employed in the clinical 
management of care within hospitals.

\section{References}

[1] Dentzler, S. (2011) Urgent Measures for an Old Problem. Health Affairs, 30, 1626. http://dx.doi.org/10.1377/hlthaff.2011.0961

[2] Iglehart, J.K. (2011) Desperately Seeking Savings: States Shift More Medicaid to Managed Care. Health Affairs, 30, 1627-1629. http://dx.doi.org/10.1377/hlthaff.2011.0836

[3] Auerbach, D.L. and Kellerman, A.L. (2011) A Decade of Health Care Cost Growth Has Wiped out Real Income Gains for an Average US Family. Health Affairs, 30, 1630-1636. http://dx.doi.org/10.1377/hlthaff.2011.0585

[4] Skinner, J., Chandra, A., Goodman, D. and Fisher, E.S. (2009) The Elusive Connection between Health Care Spending and Quality. Health Affairs, 28, 1256-1258.

[5] Hoonhout, L.H., de Bruinje, M.C., Wagner, C., Zeegers, W., Waajman, R., Spreeuwenberg, P., Asscherman, H. and van der Wal, G. (2009) Direct Medical Costs of Adverse Events in Dutch Hospitals. BMC Health Services Research, 9, 27. http://dx.doi.org/10.1186/1472-6963-9-27

[6] Rau, J. (2012) Medicare to Penalize 2211 Hospitals for Excess Readmissions. Kaiser Health News, Menlo Park, California.

[7] Sheng, W.H., Wang, J.T., Lu, D.C., Chie, W.C., Chen, Y.S. and Chang, S.C. (2005) Comparative Impact of HospitalAcquired Infections on Medical Costs, Length of Hospital Stay, and Outcome between Community Hospitals and Medical Centres. Journal of Hospital Infections, 59, 205-214. http://dx.doi.org/10.1016/j.jhin.2004.06.003

[8] Venditti, M., Falcone, M., Corrao, S., Licata, G. and Serra, P. (2009) Outcomes of Patients Hospitalized for Community-Acquired, Health Care-Associated, and Hospital Acquired Pneumonia. Annals of Internal Medicine, 150, 19-26. http://dx.doi.org/10.7326/0003-4819-150-1-200901060-00005

[9] Jencks, S.F., Williams, M.V. and Coleman, E.A. (2011) Rehospitalizations among Patients in the Medicare Fee for Service Program. New England Journal of Medicine, 364, 1582. http://dx.doi.org/10.1056/NEJMx110014

[10] Hughes, J.S., Averill, R.F. and Goldfield, N.J. (2006) Identifying Potentially Preventable Complications Using a Present on Admission Indicator. Health Care Financing Review, 27, 63-82.

[11] Fuller, R.L., McCullough, E.C., Bao, M.Z. and Averill, R.F. (2009) Estimating the Costs of Potentially Preventable Hospital Acquired Complications. Health Care Financing Review, 30, 17-32.

[12] Goldfield, N.I., McCullough, E.C., Hughes, J.S., Tang, A.M., Eastman, B., Rawlins, L.K. and Averill, R.F. (2008) Identifying Potentially Preventable Readmissions. Health Care Financing Review, 30, 75-92.

[13] Lagoe, R., Pasinski, T., Kronenberg, P., Quinn, T. and Schaengold, P. (2006) Linking Health Services at the Community Level. Canada Healthcare Quarterly, 9, 60-65. http://dx.doi.org/10.12927/hcq..18229

[14] Lagoe, R.J. and Westert, G.P. (2010) Evaluation of Hospital Inpatient Complications: A Planning Approach. BMC Health Services Research, 10, 200. http://dx.doi.org/10.1186/1472-6963-10-200

[15] Lagoe, R.J., Nanno, D.S. and Luziani, M.E. (2012) Quantitative Tools for Addressing Hospital Readmissions. BMC Research Notes, 5, 620. http://dx.doi.org/10.1186/1756-0500-5-620

[16] Iezzoni, L.J., Daely, J., Heeren, T., Foley, S.M., Fisher, E.S., Duncan, C., Hughes, J.S. and Coffman, G.A. (1994) Identifying Complications of Care Using Administrative Data. Medical Care, 32, 700-715. http://dx.doi.org/10.1097/00005650-199407000-00004

[17] Agency for Health Care Research and Quality (2003) National Healthcare Quality Report. U.S. Department of Health and Human Services, Rockville, MD.

[18] (2008) 3M Health Information Systems: Potentially Preventable Readmissions Classification System. 3M Health Information Systems, Wallingford, Conn. 
Scientific Research Publishing (SCIRP) is one of the largest Open Access journal publishers. It is currently publishing more than 200 open access, online, peer-reviewed journals covering a wide range of academic disciplines. SCIRP serves the worldwide academic communities and contributes to the progress and application of science with its publication.

Other selected journals from SCIRP are listed as below. Submit your manuscript to us via either submit@scirp.org or Online Submission Portal.
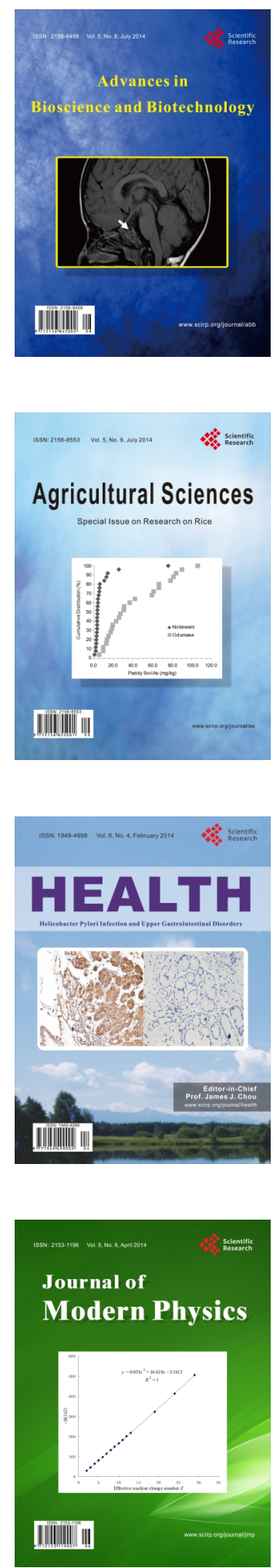
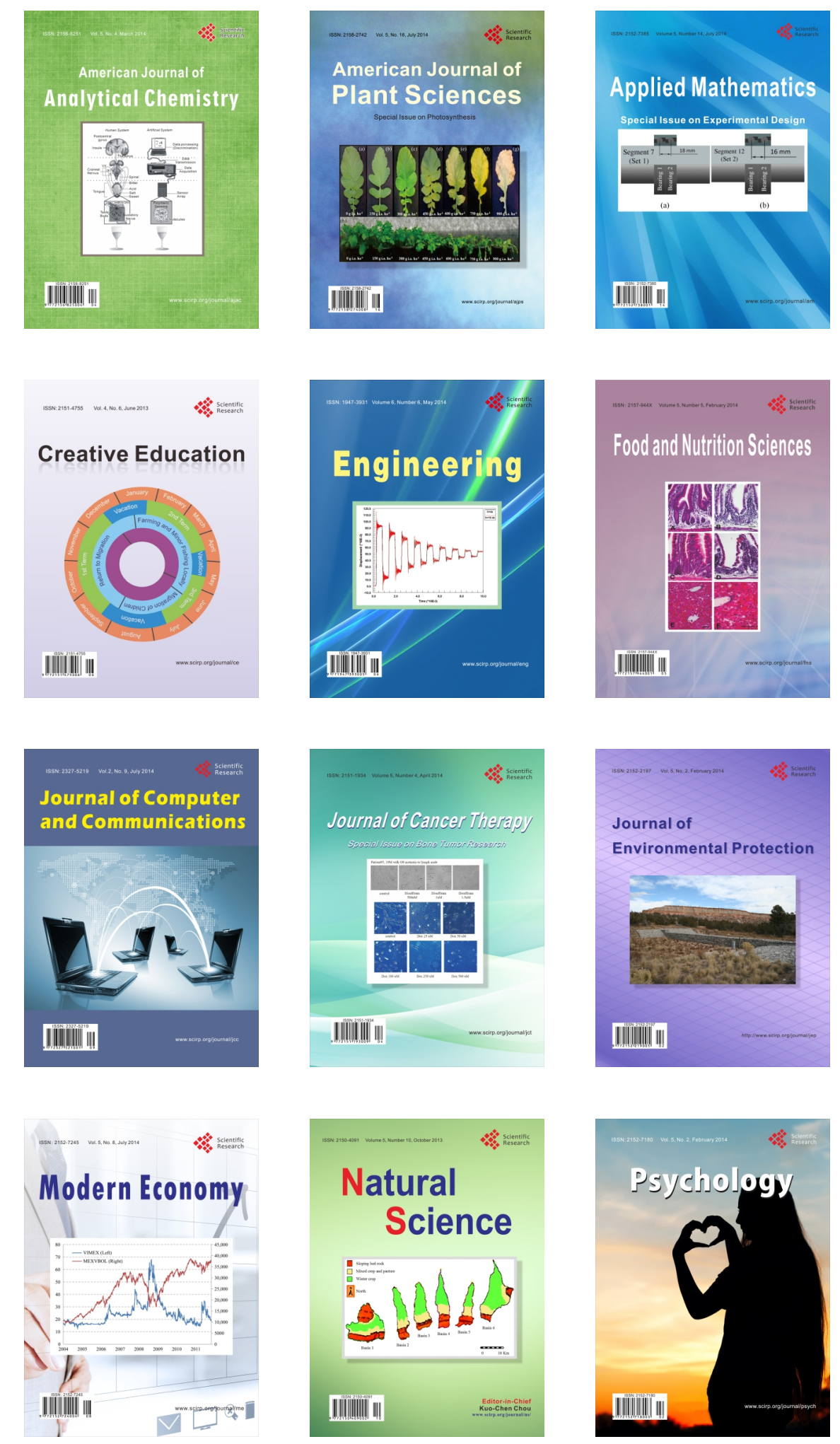